\title{
25 Research Soure \\ Synthesis of Sodium Titanates and Their Use in the Photocatalytic Degradation of No
}

\section{Marco Antonio Cueto Bastida}

CIDETEQ: Centro de Investigacion y Desarrollo Tecnologico en Electroquimica SC

\section{Yadira Guadalupe Maldonado}

CENAM: Centro Nacional de Metrologia

\section{Yolanda Reyes-Vidal}

CIDETEQ: Centro de Investigacion y Desarrollo Tecnologico en Electroquimica SC

\section{Myriam Solís-López}

CINVESTAV IPN: Centro de Investigacion y de Estudios Avanzados del Instituto Politecnico Nacional

\section{Eduardo Coutino-González}

CIO: Centro de Investigaciones en Optica AC

Fabricio Espejel Ayala ( $\nabla$ fespejel@cideteq.mx )

CIDETEQ: Centro de Investigacion y Desarrollo Tecnologico en Electroquimica SC https://orcid.org/0000-0003-2035-9590

\section{Research Article}

Keywords: hydrothermal synthesis, sodium titanate, photocatalysis, XPS analysis, NOx degradation

Posted Date: October 21st, 2021

DOl: https://doi.org/10.21203/rs.3.rs-957160/v1

License: (c) (i) This work is licensed under a Creative Commons Attribution 4.0 International License. Read Full License

Version of Record: A version of this preprint was published at Environmental Science and Pollution Research on January 28th, 2022. See the published version at https://doi.org/10.1007/s11356-02218724-y. 


\section{Abstract}

The synthesis and characterization of sodium titanates (ST), and their evaluation in the photocatalytic reduction of nitric oxide (NO) are described herein. The materials were synthesized by a hydrothermal route using $5 \mathrm{M} \mathrm{NaOH}$ as the mineralizer agent and a $\mathrm{TiO}_{2}$ content of $0.06 \mathrm{mg} / \mathrm{mL}$ (expressed as the mass ratio of $\mathrm{TiO}_{2} / \mathrm{mL}$ of $\mathrm{NaOH}$ ), at $170{ }^{\circ} \mathrm{C}$ for 48 hours, resulting in sodium tri- and hexa-titanates. $\mathrm{A}$ nanotubular morphology was observed for the ST, as proved by scanning electron microscopy (SEM); a subsequent heat-treatment at $400^{\circ} \mathrm{C}$ allowed a complete transformation of sodium tri- to hexa-titanates and an increase in bandgap. The obtained ST were impregnated with $\mathrm{Ag}^{+}$and $\mathrm{Zn}^{+}$cations, ST-Ag and ST$\mathrm{Zn}$, respectively, to tune the materials' bandgap. XPS analysis of the ST-Ag materials showed evidence of metallic Ag, pointing to the formation of silver nanoparticles, whereas for ST-Zn oxide phases were mainly spotted. The materials were evaluated for the photocatalytic reduction of $\mathrm{NO}$ using a reactor fed with a continuous flow rate of NO, generated in situ at a flow of $280 \mathrm{~mL} / \mathrm{min}$ using nitrogen and a $253 \mathrm{~nm}$ UV irradiation source. The photocatalytic tests showed that pristine ST (tri- and hexa-titanates) displayed better performance in the reduction of NO with respect to the impregnated samples (ST-Ag, ST-Zn). Maximum degradation efficiencies of $80 \%$ were achieved when $1 \mathrm{~g}$ of photocatalyst was used with a flow of $280 \mathrm{~mL} / \mathrm{min}$ and a $253 \mathrm{~nm}$ UV lamp.

\section{Introduction}

Photocatalysis is a process with important applications in environmental remediation and energy production. Nowadays, $\mathrm{TiO}_{2}$ is the more used photocatalyst in several processes, such as wastewater treatment, generation of hydrogen, degradation of pollutants in the atmosphere, and generation of electricity by photoelectron-chemical conversion of solar energy (Carbajo et al., 2017; Chiarello et al., 2017; Yan et al., 2013). However, the recombination of $\left(\mathrm{e}^{-}-\mathrm{h}^{+}\right)$pair in the surface of $\mathrm{TiO}_{2}$ when the photocatalytic process occurs and the band gap of $3.2 \mathrm{eV}$, limits the use of a small fraction of solar irradiation (approximately 4\%) in form of UV light, this has motivated the quest of novel photocatalysts or strategies to modify $\mathrm{TiO}_{2}$ to overcome these limitations (Carbajo et al., 2017). For instance, Fe-doped $\mathrm{TiO}_{2}$ material has been prepared avoiding charge recombination ( $\mathrm{Wu}$ and van de $\mathrm{Krol}, 2012$ ). The $\mathrm{Fe}-$ doped $\mathrm{TiO}_{2}$ photocatalyst was evaluated for photooxidation and photoreduction of NO by the presence of Fe and oxygen vacancies that suppresses the formation of $\mathrm{NO}_{2}$. In the mentioned work, three issues were concluded: $\mathrm{NO}_{3}{ }^{-}$generation via photooxidation, suppression of $\mathrm{NO}_{2}$ and the $\mathrm{NO}$ photoreduction to obtain $\mathrm{N}_{2}$ and $\mathrm{O}_{2}$. However, the poisoning of the catalysts was observed as ascribed to the formation of $\mathrm{NO}_{3}{ }^{-}$in the surface of the material blocking the oxygen vacancies. Other attempts include the use of titaniumbased inorganic perovskites, such as $\mathrm{SrTiO}_{3}$ decorated with $\mathrm{SrCO}_{3}$, which was tested to degrade $\mathrm{NO}$ by photocatalysis (Jin et al. 2018). Charge recombination was avoided in these materials by using a cophotocatalyst strategy $\left(\mathrm{SrTiO}_{3}-\mathrm{SrCO}_{3}\right)$. In the same line, Parayil et al. (2015) employed nitrogen-doped sodium titanate nanotubes (STT) in the photocatalytic conversion of $\mathrm{CO}_{2}$. Doped and undoped STT prepared by hydrothermal treatment showed a promising performance to reduce $\mathrm{CO}_{2}$ to $\mathrm{CH}_{4}$. ST can be 
modified by acid washing and thermal treatments to enhance their photocatalytic activity (Nguyen and Bai, 2015). Other modifications involve doping with noble metals to degrade organic matter (El Rouby et al., 2017). Their morphology is appropriate to increase the catalytic and photocatalytic activity due to tubular structure and surface areas $>200 \mathrm{~m}^{2} / \mathrm{g}$ (Machorro López et al., 2021). Hence, the use of ST in the degradation of NOx is a potential option for NOx photoreduction with the subsequent generation of $\mathrm{N}_{2}$ and $\mathrm{O}_{2}$ in comparison with the photooxidation obtained in other studies (Nguyen and Bai, 2015).

Alternative strategies have been implemented to modify the bandgap and avoid the recombination of ( $\mathrm{e}^{-}-$ $\mathrm{h}^{+}$) pair. Ibukun and Jeong (2020) achieved the $\mathrm{TiO}_{2}$ modification with silver to avoid the abovementioned issues. These authors reported that the modified $\mathrm{TiO}_{2}$ was active in the visible region; moreover, degradation kinetic of methyl blue was increased. Turkten and Bekbolet (2020) achieved the modification of $\mathrm{TiO}_{2}$ with $\mathrm{ZnO}$ to avoid the recombination of $\left(\mathrm{e}^{-}-\mathrm{h}^{+}\right)$pair and to shift the bandgap of the photocatalyst to the visible region. The material was evaluated in the degradation of humic acid demonstrating its effectivity due to the bandgap modification. Modification of titanium-related materials such as ST with $\mathrm{Ag}^{+}$and $\mathrm{Zn}^{+}$has been investigated and tested in environmental remediation studies; nevertheless, their use in as photocatalyst to degrade NOx has not been implemented.

NOx, SOx and other pollutants have a serious role in the atmospheric process of pollution. Nitric oxide (NO) is the primary pollutant emitted from combustion sources, together with a small proportion of nitrogen dioxide $\left(\mathrm{NO}_{2}\right)$, although $\mathrm{NO}$ is oxidized in the atmosphere to $\mathrm{NO}_{2} . \mathrm{NO}_{2}$ is responsible for ozone $\left(\mathrm{O}_{3}\right)$ generation. Since the 80s, three-way catalysts are used in automobiles to mainly decrease NOx levels in air (Koltsakis et al., 1998). However, the growth of automotive industry worldwide has caused negative effects in the environment, although in several countries electric cars and legislation are already a reality for the transition to zero-emission cars. However, in other countries in the Americas and Africa this transition seems still far away. Furthermore, industrial emissions are another principal source of air pollution. Hence, the NOx emission from anthropogenic and natural process is high. NOx are pollutants with significant effect in the atmosphere and the global environment. $\mathrm{NO}, \mathrm{N}_{2} \mathrm{O}$ and $\mathrm{NO}_{2}$ are the three wellknown NOx species mainly generated via anthropogenic processes. Despite the efforts made to reduce these gases, the presence of NOx in the air remains high because NOx are mainly produced by the combustion of fuels. In 2020, an excellent way to decrease pollutant emissions worldwide was demonstrated: the pandemic situation itself brought the solution when people stopped their mobility. For instance, in China, a decrease in NOx emissions was observed: NOx emissions decreased by $50 \%$ in East China in the period from January 23 to February 9 (Zhang et al., 2020). Economic impacts were evident; nevertheless, as long as the economic transition to less human mobility is not implemented, pollution reduction technologies must be improved. Therefore, this work studied the preparation of ST by hydrothermal treatment and their evaluation in the photocatalytic degradation of NO. In particular, ST were prepared with a low concentration of $\mathrm{NaOH}$. In addition, silver and zinc oxide modified ST were tested to demonstrate their efficiency in the photoreduction of $\mathrm{NO}$ to generate $\mathrm{N}_{2}$ and $\mathrm{O}_{2}$.

\section{Materials And Methods}


ST were synthesized by a modified Kasuga procedure (Kasuga et al. 1998). Briefly, $3 \mathrm{~g}$ of commercial $\mathrm{TiO}_{2}$ was placed with a $\mathrm{NaOH}$ solution (2.5 or $5 \mathrm{M}, 500 \mathrm{~mL}$ ) at room temperature for $24 \mathrm{~h}$ with continuous magnetic stirring. Then, the mixture was transferred to a $1 \mathrm{~L}$ Teflon-lined stainless steel autoclave and heated at $170^{\circ} \mathrm{C}$ for $48 \mathrm{~h}$. Finally, the obtained product was recovered by filtration and washed several times with distilled water until $\mathrm{pH} 7$ was reached, then it was dried at $110^{\circ} \mathrm{C}$. Additionally, a batch of dried samples was annealed at $400^{\circ} \mathrm{C}$ in air using a temperature ramp of $10^{\circ} \mathrm{C} / \mathrm{min}$ to determine its effect on the ST phases, the samples were labeled as CST, where the C stands for "calcined".

Synthesis of modified ST

Modified ST materials were synthesized to modify the bandgap and avoid the recombination of $\left(\mathrm{e}^{-}-\mathrm{h}^{+}\right)$ pairs to increase their photocatalytic activity (Wodka et al., 2010; Albiter et al., 2015). The preparation procedure was as follows: the appropriate amount of $\mathrm{AgNO}_{3}$ or $\mathrm{Zn}\left(\mathrm{NO}_{3}\right)-6 \mathrm{H}_{2} \mathrm{O}$, calculated for $5 \%$ in weight, was dissolved in $1 \mathrm{~mL}$ of $\mathrm{H}_{2} \mathrm{O}$, and then $1 \mathrm{~g}$ of ST was added to the above solutions. All samples were dried at $100^{\circ} \mathrm{C}$ and calcined at $400^{\circ} \mathrm{C}$ for 2 hours with a temperature ramp of $10^{\circ} \mathrm{C} / \mathrm{min}$. The obtained samples were denoted as ST-Ag5 and ST-Zn5.

Characterization

The crystalline structure of the samples was analyzed by X-ray diffraction using a Bruker D8 Advance Xray Diffractometer (XRD) with a Cu- $\lambda$ radiation $(\lambda=0.15406 \AA \hat{)})$ with a Nickel filter operating at $40 \mathrm{kV}$ and $40 \mathrm{~mA}$. The data were collected in the $2 \theta$ range from $5^{\circ}$ to $50^{\circ}$ with a scan rate of $0.02^{\circ}$. The morphology of the samples was observed by SEM using a JSM-6510 LV SEM (JEOL). The elemental analysis was carried out by energy-dispersive X-ray analysis (EDX). Transmission Electron Microscopy (Jeol, JEM1400Plus) was also used for the morphological studies. The surface chemical bonding was analyzed by X-ray photoelectron spectroscopy (XPS), using a Thermo Scientific K-Alpha instrument equipped with Al Ka X-ray source at energy of $1486.6 \mathrm{eV}$, measuring points of $200 \times 200 \mathrm{~mm}$. Calibration was confirmed by adventitious carbon C1s at $285 \mathrm{eV}$. Spectrum deconvolution was carried out using a Gaussian model. The thermal stability of the samples was investigated by thermogravimetric analysis (TGA) in a Netzsch STA $449 \mathrm{~F} 5$ Jupiter from room temperature to $900^{\circ} \mathrm{C}$. The samples were heated with $10^{\circ} \mathrm{C} / \mathrm{min}$ from room temperature to $900^{\circ} \mathrm{C}$, under a nitrogen flow of $50 \mathrm{~mL} / \mathrm{min}$. The optical characterization of the samples was carried out by UV-Vis diffuse reflectance with a Shimadzu UV-2600 spectrophotometer. The diffuse reflectance spectra (DRS) were recorded in the range of 200 to $800 \mathrm{~nm}$.

Photocatalysts evaluation

NOx generation was carried out using $\mathrm{HNO}_{3}$ and metallic copper according to reaction 1 and 2:

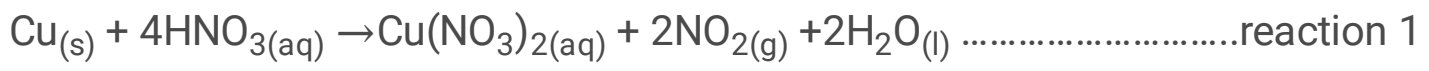


$3 \mathrm{Cu}(\mathrm{s})+8 \mathrm{HNO}_{3(\mathrm{aq})} \rightarrow 3 \mathrm{Cu}\left(\mathrm{NO}_{3}\right)_{2(\mathrm{aq})}+2 \mathrm{NO}$

$(g)+4 \mathrm{H}_{2} \mathrm{O}_{(\mathrm{l})}$ reaction 2

In reaction 2, the $\mathrm{NO}$ generation was carried out in the absence of oxygen. $\mathrm{Cu}$ and $\mathrm{HNO}_{3}$ were mixed in a Buchner flask to generate NO. $\mathrm{N}_{2}$ was used as carrier gas using a flow of $280 \mathrm{~mL} / \mathrm{min}$. Gaseous flow passed through a photocatalysis reactor consisting of a flask with a pencil-type lamp as a source of monochromatic radiation at $253 \mathrm{~nm}$, where 1000 milligrams of the photocatalysis in powder form was loaded. The photocatalytic activity of the samples was evaluated in an experimental arrangement as shown in Figure 1, where a continuous flow of $\mathrm{N}_{2}$ (used as carrier of in-situ produced NO) was fed in the photocatalytic reactor. The mixture of gases were transported to the abatement chamber passing through the surface of the photocatalyst and irradiated at $253 \mathrm{~nm}$ (UV) with the monochromatic source inside the chamber for 10 minutes. An AMPRO analyzer was used to measure the concentration of the gas products.

Prior to photocatalytic evaluation, a statistical analysis of variance (ANOVA) of initial NO concentration was carried out (Table 1). Twenty experiments were recorded without the use of a photocatalyst.

Likewise, a t-test was performed for samples assuming equal variances. The previous analysis allowed to estimate a standard deviation $(\sigma)=71.67$ and a mean $=641 \mathrm{ppm}$ of initial concentration NO with an interval of $\pm 31.41 \mathrm{ppm}$. From this, the degradation was measured with respect to the obtained values.

Table 1

ANOVA for the production of NO.

\begin{tabular}{|llllll|}
\hline $\begin{array}{l}\text { Origin of the } \\
\text { variations }\end{array}$ & $\begin{array}{l}\text { Sum of } \\
\text { squares }\end{array}$ & $\begin{array}{l}\text { Degrees of } \\
\text { freedom }\end{array}$ & $\begin{array}{l}\text { Average of } \\
\text { squares }\end{array}$ & $\begin{array}{l}\text { F- } \\
\text { value }\end{array}$ & Probability \\
\hline Between group & 1584.2 & 1 & 1584.2 & 4.4138 & 0.5924 \\
\hline Whitin-group & 96016.6 & 18 & 5334.2 & & \\
\hline Total & 97600.8 & 19 & & & \\
\hline
\end{tabular}

\section{Results And Discussion}

In Figure 2, X-ray diffraction (XRD) patterns of $\mathrm{TiO}_{2}, \mathrm{ST}, \mathrm{CST}$ and modified ST are displayed. Two main crystalline planes $\left(\begin{array}{lll}1 & 0 & 1\end{array}\right)$ and $\left(\begin{array}{lll}1 & 1 & 0\end{array}\right), 25.3$ and $27.42 \theta$ respectively, were identified corresponding to anatase and rutile only in the $\mathrm{TiO}_{2}$ sample. However, the patterns of the particles obtained after the hydrothermal treatment, pointed to the fading of the characteristic peaks of P25 powder and new peaks corresponding to ST appeared. The diffraction peaks at $\sim 10,24,28$ and $482 \theta$, could be clearly identified and are in agreement with a titanate layered structure, Figure 2(a-e). The broad peaks at 10 and $282 \theta$ correspond to interlayer spacing in layered titanates and reveal the nanotube structure (Hernández and Medina 2015; Vattikuti et al. 2018). The peaks at 24 and $482 \theta$ indicate the presence of hydrogen and sodium trititanates. Considering these facts, the XRD patterns can be assigned to trititanate $(\mathrm{H}, \mathrm{Na})_{2} \mathrm{Ti}_{3} \mathrm{O}_{7}$ with different interlayer spacing; for example, $\mathrm{Ti}_{6} \mathrm{O}_{13}, \mathrm{Ti}_{6} \mathrm{O}_{12}$, and $\mathrm{Ti}_{9} \mathrm{O}_{18}$. Diffractogram of thermally treated ST was similar to that of non-calcined ST, Figure 1 (d). There is a modification in the low angle 10 
$2 \theta$, corresponding to a partial collapse in the tubular structure from thermal treatment (Lee et al., 2007). The deterioration of the tubular structure may be attributed to the dehydration of inter-layered $\mathrm{OH}$ anion which led to the contraction and breaking of tube structures. During the annealing treatment, the chemical bonds such as $\mathrm{H}_{2} \mathrm{O}$ and $-\mathrm{OH}$ are removed from the titanate structure, driving to the change of crystalline form and, at the same time, degrading the nanotube morphology. Figures 1 (a) and 1(b) show the diffractograms of the bare and Ag or Zn-loaded catalysts (ST+Zn5 and ST+Ag5), where sodium titanate was the main phase observed. Due to the low concentration of co-catalysts, there is an absence of reflections of $\mathrm{Ag}$ or $\mathrm{Zn}$ species in the patterns. In the case of ST+Ag5 pattern, signal broadening occurs at low angles. However, signals associated to $\mathrm{Ag}$ in the diffractogram at 38 and $44^{\circ}$ were not spotted (Barrocas et al., 2016). A change at $10^{\circ}$ signal was observed in the ST+Zn5 diffractogram, this could be attributed to the incomplete transformation of structural nanotubes (Li et al., 2012); yet, there is an increase at $28^{\circ}$ characteristic of ( 310 ) plane of $\mathrm{Zn}$. At $2 \theta$ of $47^{\circ}$ a characteristic peak corresponding to plane (2 00 ) of anatase disappeared. Three planes (llll), ( $\left.\begin{array}{lll}3 & 0 & 1\end{array}\right)$ and $\left(\begin{array}{lll}0 & 2 & 1\end{array}\right)$ at $9.4,27.5$ and $48.32 \theta$, respectively, evidence the transformation of $\mathrm{TiO}_{2}$ to $\mathrm{ST}$. Titanate species were modified by changing the $\mathrm{NaOH}$ concentration, from 2.5 to $5 \mathrm{M}$, and time was varied from 24 to 48 hours (Figure 2).

SEM analysis

According to Figure 3 , the morphology of $\mathrm{ST}$ depends on $\mathrm{NaOH}$ concentration and time in the hydrothermal treatment. Agglomerated particles were observed, Figures $3 a$ and $2 \mathrm{~b}$ correspond to ST synthesized from $2.5 \mathrm{M} \mathrm{NaOH}$ solution and 24 hours at $170^{\circ} \mathrm{C}$. In contrast, Figures $3 \mathrm{c}$ and $3 \mathrm{~d}$ show tubular particles of ST. Those samples were obtained with high $\mathrm{NaOH}$ concentrations during 48 hours of hydrothermal treatment. Tubular aspects are related to an interlayer coordination of non-coordinate $\mathrm{Ti}$ and $O$ atoms (Saponjic et al. 2005; Morgan et al. 2008); these micrographs exhibit the formation of tubular structures. The length of the obtained ST is up to few micrometers and $200 \mathrm{~nm}$ width. Figures $3 e$ and $3 f$ correspond to ST+Ag5 and ST+Zn5, respectively. It can be observed that in both cases there is a loss of the tubular structure due to the thermal treatment during the impregnation process.

EDX analysis is shown in Table 3. $\mathrm{Na}_{2} \mathrm{Ti}_{3} \mathrm{O}_{7}$ and $\mathrm{Na}_{2} \mathrm{Ti}_{7} \mathrm{O}_{13}$ have theoretical values of $\mathrm{Ti} / \mathrm{Na}=1.5$ and 3 , respectively, while $\mathrm{O} / \mathrm{Ti}$ values are 2.3 and 2.16. Values of $\mathrm{Ti} / \mathrm{Na}$ and $\mathrm{O} / \mathrm{Ti}$ in Table 2 indicate the presence of residual $\mathrm{TiO}_{2}$, according to quantification by Rietveld analysis (results not shown). Thermal treatment did not display a significant effect in the composition of ST, although the anatase to rutile phase transition has been previously reported (Nguyen and Bai, 2015), owing the loss of $\mathrm{Na}$ atoms from the ionic substitution of $\mathrm{Na}^{+}$by $\mathrm{H}^{+}$when the washing is carried out to reach a pH of 7. When $\mathrm{Ag}$ is impregnated in the ST material, Ti/Na increased while O/Ti decreased, pointing to a $\mathrm{Na}^{+} / \mathrm{Ag}^{+}$ion exchange. When ST is modified with $\mathrm{Zn}, \mathrm{Ti} / \mathrm{Na}$ increased possibly from the ion exchange of $\mathrm{Na}$ with $\mathrm{Zn}$; however, $\mathrm{O} / \mathrm{Ti}$ indicates the formation of $\mathrm{ZnO}$ in the ST. XPS analysis was conducted to verify this hypothesis (Figure 4). 
Table 2

Elemental composition of the synthesized ST determined by EDS.

\begin{tabular}{|c|c|c|c|c|c|c|c|c|}
\hline \multirow[t]{2}{*}{ Sample } & \multicolumn{5}{|c|}{ Elemental composition, atomic \% } & \multirow[t]{2}{*}{$\mathrm{Ti} / \mathrm{Na}$} & \multirow[t]{2}{*}{$0 / \mathrm{Ti}$} & \multirow{2}{*}{$\begin{array}{l}\mathrm{Ti} / \mathrm{M} \\
\mathrm{M}=\mathrm{Ag}, \mathrm{Zn}\end{array}$} \\
\hline & $\mathrm{Ti}$ & $\mathrm{Na}$ & 0 & $\mathrm{Ag}$ & $\mathrm{Zn}$ & & & \\
\hline $\mathrm{TiO}_{2}$ & 35.00 & 0 & 65.00 & 0 & 0 & - & 1.85 & -- \\
\hline ST & 45.03 & 8.9 & 46.07 & 0 & 0 & 5.05 & 1.02 & -- \\
\hline CST & 45.79 & 7.59 & 46.61 & 0 & 0 & 6.03 & 1.01 & - \\
\hline ST+Ag5 & 47.10 & 8.26 & 39.48 & 5.16 & 0 & 5.70 & 0.83 & 9.12 \\
\hline$S T+Z n 5$ & 45.57 & 5.63 & 46.58 & 0 & 2.22 & 8.09 & 1.02 & 20.52 \\
\hline
\end{tabular}

ST and CST XPS survey spectra are similar, indicating that chemical changes are not caused by the thermal treatment of ST. For ST+Ag5 and ST+Zn5, signals of Ag and Zn appeared with a significant intensity. Quantification by XPS of ST samples is displayed in Table 3.

Table 3

Elemental composition of ST determined from XPS.

\begin{tabular}{|c|c|c|c|c|c|c|c|c|}
\hline \multirow[t]{2}{*}{ Samples } & \multicolumn{5}{|c|}{ Elemental composition, \% } & \multirow[t]{2}{*}{$\mathrm{Ti} / \mathrm{Na}$} & \multirow[t]{2}{*}{ 0/Ti } & \multirow{2}{*}{$\begin{array}{l}\mathrm{Ti} / \mathrm{M} \\
\mathrm{M}=\mathrm{Ag}, \mathrm{Zn}\end{array}$} \\
\hline & $\mathrm{Na}$ & $\mathrm{Ti}$ & 0 & $\mathrm{Ag}$ & $\mathrm{Zn}$ & & & \\
\hline ST & 13.67 & 27.96 & 58.37 & 0 & 0 & 2.04 & 2.08 & - \\
\hline CST & 13.64 & 28.60 & 57.76 & 0 & 0 & 2.09 & 2.01 & - \\
\hline ST+Ag5 & 11.82 & 22.36 & 57.70 & 8.10 & 0 & 1.89 & 2.58 & 2.76 \\
\hline $\mathrm{ST}+\mathrm{Zn} 5$ & 15.19 & 26.25 & 50.81 & 0 & 7.75 & 1.72 & 1.93 & 3.40 \\
\hline
\end{tabular}

Values of $\mathrm{Ti} / \mathrm{Na}$ and $\mathrm{O} / \mathrm{Ti}$ ratios in $\mathrm{ST}$ indicate the predominant formation of sodium trititanate, this being the main phase from the hydrothermal treatment applied. XPS analysis of modified ST indicates the above in Table 3: ionic exchange of $\mathrm{Na}^{+}$by $\mathrm{Ag}^{+}$and $\mathrm{ZnO}$ formation. As expected, the values of elemental composition shown in Table 4 are different with respect to Table 3, due to the difference in the volume of the analyzed sample in each technique. Analysis from XPS guarantees the surface inspection of the samples. Surface composition change in the calcined and modified ST was expected; however, for the CST composition this change did not occur. In the modified ST a slight decrease in the Ti/Na ratio was observed, due to the migration of $\mathrm{Na}$ atoms from the inner part of the sample to the surface, causing an increase of $\mathrm{Na}$ in the surface and a change in the surrounding chemical composition (Figure 4).

Characteristic signals of $\mathrm{Ti}$ at 459 and $465 \mathrm{eV}$ which correspond to $2 \mathrm{p}_{3 / 2}$ and $2 \mathrm{p}_{1 / 2}$ are shown in Figure 5 . Signals are attributed to $\mathrm{Ti}^{4+}$ ions forming an octahedral structure of titanates (Kurra et al. 2019). Figure $5 a$ shows a doublet signal, corresponding to $T i 2 p_{3 / 2}$ and $T i 2 p_{1 / 2}$ with binding energy at $465 \mathrm{eV}\left(\mathrm{Ti} 2 \mathrm{p}_{3 / 2}\right)$ 
and 459 (Ti2 $\mathrm{p}_{1 / 2}$ ) (Coelho et al., 2016). Na substitution by Ag and Zn was corroborated by XPS. In Figure $5 \mathrm{a}$, the Ti signals for ST and CST appear in the same binding energy, while the Ti signals for ST+Ag5 and $\mathrm{ST}+\mathrm{Zn} 5$ are shifted to lower energies, indicating that the aforementioned atoms were incorporated into the ST. This same behavior was observed in the case of Na spectra analysis, showing a slight shift for the modified ST. The $01 \mathrm{~s}$ signal appears at $530 \mathrm{eV}$ in all of the ST, indicating the formation of $\mathrm{O}^{2-}$ oxygen-titanium bonds (Hernández-Hipólito et al. 2014). Figure 5a shows a shift in the Ti2p band, corresponding to ST+5Ag, it is shifted to lower energy by approximately $0.49 \mathrm{eV}$ units compared to ST and CST. This shifting is attributed to the substitution of $\mathrm{Na}$ with Ag ions, which indicates the movement of electrons over a longer distance in the Ti nucleus in the atomic expansion of Ti (Barrocas et al. 2016). In the case of ST and CST, signals appear at $1072 \mathrm{eV}$ revealing the presence of $\mathrm{Na}$ ions in the titanate (Marciniuk et al. 2014). Moreover, in the case of the Ag3d a difference of $6 \mathrm{eV}$ between $\mathrm{Ag} \mathrm{d}_{5 / 2}(368 \mathrm{eV}$ ) and $A g 3 d_{3 / 2}(374 \mathrm{eV}$ ) is characteristic of the metallic state of $\mathrm{Ag}$ (Duan et al., 2017). Figure $5 \mathrm{~d}$ shows the XPS spectra of ST+5Zn emphasizing the signals at 1021 and $1044 \mathrm{eV}$. The splitting of Zn2p orbitals in $\mathrm{ZnO}$ is observed (Wang et al. 2009). A shift of $0.81 \mathrm{eV}$ in the Ti2p is observed, suggesting a change in the $\mathrm{Ti}$ environment in coordination with $\mathrm{Zn}$, modifying the ionic radius of $\mathrm{Ti}$. In this case, the presence of octahedral and tetrahedral titanium is possible (Cho et al. 2014; Wang et al. 2009). However, the samples in this study only showed the octahedral structure where the metallic atoms do not modify the main structure of the ST. XPS analysis showed that the ST is not affected in its elemental composition with the thermal treatment at $400^{\circ} \mathrm{C}$. SEM images and EDS analysis corroborate the above mentioned, although the tubular structure in the ST collapsed. ST+5Ag and ST+5Zn show a different behavior because the binding energies indicate that the ST are not forming bonds with the metallic elements. Additionally, $\mathrm{Na}$ ions are exchanged for $\mathrm{Zn}$ and Ag. TEM images show the morphology of the samples prepared herein (Figure 6).

TEM images show the tubular structure of ST, Figure 5a, although this morphology collapsed when treated at $400^{\circ} \mathrm{C}$, Figure $5 \mathrm{~b}$. For the modified ST, small particles are observed in each case, demonstrating the formation of nanoparticles through ion exchange. Thermogravimetric (TGA) analysis was used to explain the morphology collapse. Figure 7 shows the TGA/DSC analysis of the samples.

Figure 7 shows the thermogravimetric curves of the ST materials obtained. The maximum weight loss occurs at lower temperatures, where the dehydration of physisorbed water takes place. The single stage weight loss of roughly $10 \%$ occurs up to $200^{\circ} \mathrm{C}$. This process is reflected as an endothermic peak on a DSC curve. From this temperature the weight decreases slowly and continuously up to nearly $700^{\circ} \mathrm{C}$. At $\mathrm{T}$ $\leq 300^{\circ} \mathrm{C}$ the dehydration of interlayered $\mathrm{OH}$ groups could reduce the interlayer distance, but does not destroy the tubular shape. When the temperature is $>300^{\circ} \mathrm{C}$, the dehydration of interlayered $\mathrm{OH}$ groups induced the change of crystalline form and, at the same time, the nanotube morphology is destroyed. A broad exothermic peak in a temperature range from 300 to $800^{\circ} \mathrm{C}$ in the DSC curve could indicate that the synthesized ST lose the interlayered $\mathrm{OH}$ groups in a broader range, while the interlayered $\mathrm{OH}$ groups remain in the structure up to $600^{\circ} \mathrm{C}$ or the cleavage of both type of $\mathrm{OH}$ groups occurs simultaneously. Between $200-300^{\circ} \mathrm{C}$ an exothermic reaction occurs, this process is attributed to the hexa- to tri-titanate 
transformation (Lee et al. 2007). At $400-600^{\circ} \mathrm{C}$ an endothermic process is observed, indicating the collapse of the tubular structure, forming spherical particles.

A comparison of the UV-vis spectra of the prepared ST showed the absorbance of ST with and without modifications in a range of 600-200 nm (Figure not shown). Figure 8 shows the UV-vis spectra modified with the Kubelka-Munk function, showing a high absorption between 325-340 nm for ST and CST, while for $\mathrm{ST}+\mathrm{Ag} 5$ and $\mathrm{ST}+\mathrm{Zn} 5$ the absorption is observed at $355 \mathrm{~nm}$. $\mathrm{TiO}_{2}$ spectrum shows an absorption at $350 \mathrm{~nm}$, indicating a band shift for the prepared ST due to photon scattering caused by defects in the ST crystals (Benzarouk et al. 2012). Eg-values are shown in the Table 4.

Table 4

\begin{tabular}{|c|c|}
\hline \multicolumn{2}{|c|}{$\begin{array}{l}\text { Optical Eg obtained } \\
\text { from the Kubelka- } \\
\text { Munk function } \\
\text { applied to DRS } \\
\text { spectroscopy of } \\
\text { prepared ST. }\end{array}$} \\
\hline Sample & $\mathrm{Eg}(\mathrm{eV})$ \\
\hline $\mathrm{TiO}_{2}$ & 3.5 \\
\hline ST & 3.8 \\
\hline CST & 3.6 \\
\hline ST+Ag5 & 3.4-3.5 \\
\hline$S T+Z n 5$ & 3.4-3.5 \\
\hline
\end{tabular}

Eg- $\mathrm{TiO}_{2}$ value changed from 3.5 to $3.8 \mathrm{eV}$ upon transformation to sodium titanate. Besides, the Eg-CST value decreased to $3.6 \mathrm{eV}$ due to recrystallization and morphology change caused by the thermal treatment. Impregnation of ST with Ag and Zn promoted a slight change of Eg due to the Burstein-Moss effect (Jayaraj et al., 2002). The change in the absorption bands is a consequence of the increase of carrier charges and the blocking of low energy transitions due to the doping and calcination treatment of the ST. This promoted an increase in the Fermi level, leading to the modification of Eg (Achour et al. 2007). It is preferable that the energy levels decrease to active the photocatalyst by broadening the range of light that can be useful (UV and visible).

NO abatement

According to reactions 1 and 2, $\mathrm{NO}$ was produced by mixing certain amounts of $\mathrm{Cu}$ and $\mathrm{HNO}_{3}$ obtaining a maximum concentration of $641 \mathrm{ppm}$ on average. Figure 9 shows the comparison in NO photodegradation when using $\mathrm{ST}$ and $\mathrm{TiO}_{2}$.

Figure 9a shows the NO concentration as a function of the amount of copper in reaction 2 . There is practically no degradation of $\mathrm{NO}$ (conversion to $\mathrm{NO}_{2}$ ) by the exposure under UV light ( $253 \mathrm{~nm}$ ). It is 
important to note that the NO concentration found in the present work were higher than those reported in previous studies, for instance, Ma et al., (2015) achieved the photocatalysis process with $400 \mathrm{ppb}$ of NO; Duan et al., (2017) used $450 \mathrm{ppb}$ of NO. The concentration tested herein was selected considering the maximum NO emission concentration in a car with an air:fuel ratio of 14.64:1 (by mass) which is lower than the stoichiometric level (Dey and Mehta, 2020). $\mathrm{TiO}_{2}$ exhibited a degradation percentage of about $50 \%$ with an initial load of 0.2 and $0.4 \mathrm{~g}$; although, as the amount of photocatalyst increased, the NO degradation remained unchanged. This means that $\mathrm{TiO}_{2}$ decreased the $\mathrm{NO}$ concentration up to $320 \mathrm{ppm}$ being significant in the total emissions in a car with the above air:fuel ratio. Moreover, higher loadings of $\mathrm{TiO}_{2}$ are not favorable for the photoreduction of $\mathrm{NO}$ : with $0.6,0.8$ and $1 \mathrm{~g}$ of $\mathrm{TiO}_{2}$ there was an increase in $\mathrm{C} / \mathrm{Co}$ possibly due to adsorption phenomena. Namely, when $\mathrm{NO}$ is on the photoreactor $\mathrm{TiO}_{2}$ adsorbs it by blocking sites for the photocatalysis process. Carrera et al., (2007) reported a similar behavior: after exposure time, the NO concentration increased, possibly also due to the blocking of the photocatalytic sites on the $\mathrm{TiO}_{2}$ surface when a low $\mathrm{NO}$ concentration ( $50 \mathrm{ppm}$ ) was tested. Another possible reason for this behavior is the non-homogeneous distribution of the sample in the photoreactor, which prevented the use of the total $\mathrm{TiO}_{2}$ area. However, this explanation is opposite to that of the other photocatalyst materials, since ST, with and without modification, showed higher performance increasing NO photodegradation with higher loadings of the photocatalyst.

The most efficient synthesized photocatalyst was ST using $1.0 \mathrm{~g}$ in the experiments. The NO degradation occurred in stages and is relatively similar to that obtained when using other photocatalyst $65 \%$ of degradation). Compared to the same material loading, CST degraded $62 \%$ of NO, while TS+Ag5 and TS+Zn 5 showed a degradation percentage of $45 \%$ and $40 \%$, respectively. The higher percentage of NO degradation is attributable to a higher surface area in ST, $>210 \mathrm{~m}^{2} / \mathrm{g}$ (reported for Machorro López et al., 2021), than in other photocatalysts. Possibly, the thermal treatment on the modified ST affected the performance by reducing the surface area and active sites to achieve the photocatalytic process. This is best related to the bandgap of the ST; it is consistent to say that the bandgap, together with the surface area of the sample, have a greater influence on the photocatalytic effect of the synthesized materials. Therefore, the thermal treatment in the ST was not suitable for degrading NO.

One of the possible routes for NO photoreduction has been described in terms of the catalytic sites on the surface, which contains tetrahedrally coordinated Ti. This species has been reported by Anpo et al. (1997) as a catalytic site that favors the decomposition of $\mathrm{NO}$ to $\mathrm{N}_{2}$ and $\mathrm{O}_{2}$, using Ti-modified zeolites. Since most $\mathrm{Ti}$ ions on the surface of the photocatalyst have a 5 -coordination, a single oxygen vacancy could lead to the formation of a reducing site. Wu and van de Krol (2012) described the mechanism of NO reduction where $\mathrm{NO}$ molecules are captured at sites where oxygen vacancies act as photocatalytic sites. In the work of Nguyen and Bai (2015), photodegradation of NOx was reported through the oxidation of $\mathrm{NO}$ and $\mathrm{NO}_{2}$ using ST treated with acid, while in the present work the photoreduction of NO was demonstrated. Furthermore, the adsorption of NO did not occur under the conditions described herein.

\section{Conclusions}


This work demonstrated the not-extreme hydrothermal conditions to synthesize sodium titanates; specifically, high concentration of $\mathrm{NaOH}$ was avoided to generate an environmentally friendly process with low consumption of water and other reactants. Furthermore, the photocatalytic activity of sodium titanates, synthesized from hydrothermal treatment, was confirmed to degrade NO by reduction. Sodium titanate was modified with $\mathrm{Ag}$ and $\mathrm{Zn}$ to increase the photocatalityc activity; however, the highest activity to degrade NO was reported with sodium titanate without modification. This was achieved due to the different morphology of sodium titanate, nanotubular versus non-nanotubular forms of modified sodium titanate. Photo reduction of NOx was carried out and compared with other works to degrade this pollutant. The advantage over these is that no byproducts are generated in the reaction, being nitrogen and oxygen the only byproducts generated.

\section{Declarations}

\section{Acknowledgments}

The authors thank to CONACYT for financial support from the Ciencia-Básica fund (grant 255456). A. Cueto Bastida gratefully acknowledges the support provided by CONACYT in the form of a master's scholarship.

\section{References}

1. Carbajo J, Bahamonde A, Faraldos $M$ (2017) Photocatalyst performance in wastewater treatment applications: towards the role of $\mathrm{TiO}_{2}$ properties. Mol Catal, (434), 164-174

2. Chiarello GL, Dozzi MV, Selli E (2017) $\mathrm{TiO}_{2}$-based materials for photocatalytic hydrogen production. J Energ Chem 26(2):250-258

3. Yan H, Wang X, Yao M, Yao X (2013) Band structure design of semiconductors for enhanced phtocaralytic activity: The case of $\mathrm{TiO}_{2}$. Prog Nat Sci: Mate Inter 23(4):402-407

4. Wu Q, van de Krol R (2012) Selective photoreduction of nitric oxide to nitrogen by nanostructured $\mathrm{TiO}_{2}$ photocatalysts: role of oxygen vacancies and iron dopant. J Amer Chem Soc 134(22):93699375

5. Jin S, Dong G, Luo J, Ma F, Wang Ch (2018) Improved photocatalytic NO removal activity of $\mathrm{SrTiO}_{3}$ by using $\mathrm{SrCO}_{3}$ as a new co-catalyst. Appl Catal B: Environ 227:24-34

6. Parayil SK, Razzaq A, Park S, Kim HR, Grimes CA, In A (2015) Photocatalytic conversion of $\mathrm{CO}_{2}$ to hydorcarbon fuel using carbon and nitrogen co-doped sodium titanate nanotubes. Appl Catals A: Gen 498(5):205-213

7. Nguyen $\mathrm{N}$, Bai H (2015) Effect of washing $\mathrm{pH}$ on the properties of titanate nanotubes and its activity for photocatalytic oxidation of $\mathrm{NO}$ and $\mathrm{NO}_{2}$. Appl Surf Sci 355:672-680

8. El Rouby WMA, Comeseña-Hermo M, Testa-Anta M, Carbó-Argibay E, Salgueriño V, Pérez-Lorenzo M, Correa-Duarte MA (2017) Au-decorated sodium titanate nanotubes as high-performance selective 
photocatalysts for pollutant degradation. J Phy D: Appl Phy 50(14):144002

9. Machorro López JJ, Lázaro AL, Rodríguez-Valadez FJ, Espejel-Ayala F (2021) Synthesis of sodium titanate catalysts using a factorial design for biodiesel production. Environ Prog Sustainable Energy 40(1):13475

10. Ibukun O, Jeong HK (2020) Taioring titanium dioxide by silver particles for photocatalysis. Curr Appl Phy 29:23-28

11. Turkten N, Bekbolet M (2020) Photocatalytic performance of titanium dioxide and zinc oxide binary system on degradation of humic matter. J Photochem Photobiol A: Chem. (401), 122748

12. Koltsakis GC, Kandylas IP, Stamatelos AM (1998) Three way catalytic converter modeling and applications. Chem Eng Commun 164:153-189

13. Zhang R, Zhang Y, Lin H, Feng X, Fu T-M, Wang Y (2020) NOx emission reduction and recovery during COVID-19 in east China. Atmos 11(4):433

14. Kasuga T, Hiramatsu M, Hoson A, Sekino T, Niihara K (1998) Formation of titanium oxide nanotube. Langmuir 14:3160-3163

15. Wodka D, Bielanska E, Soha RP, Elzbieciak-Wodka M, Gurgul J, Nowak P, Warszynski P, Kumakiri I (2010) Photocatalytic activity of titanium dioxide modified by silver nanoparticles. Appl Mater Interfaces 2(7):1945-1953

16. Albiter E, Valenzuela MA, Alfaro S, Valverde-Aguilar G, Martínez-Pallares FM (2015) Photocatalytic deposition of $\mathrm{Ag}$ nanoparticles on $\mathrm{TiO}_{2}$ : metal precursor effect on the structural and photoactivity properties. J Saudi Chem Soc 19:563-573

17. Hernández RA, Medina RI (2015) Photocatalytic Semiconductors. Springer International Publishing Switzerland. Doi:10.1007/978-3-319-10999-2

18. Vattikuti P, Kumar Reddy P, Nagayothi Jaesool P (2018) Hydrothermally synthesized $\mathrm{Na}_{2} \mathrm{Ti}_{3} \mathrm{O}_{7}$ nanotube- $\mathrm{V}_{2} \mathrm{O}_{5}$ heterostructures with improved photocatalytic degradation and hydrogen evolutionIts photocorrosion suppression. J Alloys Compd 740(5):574-586

19. Lee CK, Wang CC, Lyu MD, Juang LC, Liu SS, Hung SH (2007) Effects of sodium content and calcination temperature on the morphology, structure and photocatalytic activity of nanotubular titanates. J Colloid Inter Sci 316(2):562-569

20. Barrocas B, Nunes CD, Carvalho ML, Monteiro OC (2016) Titanate nanotubes sensitized with silver nanoparticles: synthesis, characterization and in-situ pollutants photodegradation. Appl Surf Sci $385: 18-27$

21. Li MJ, Chi ZY, Wu ChY (2012) Morpholoy, chemical composition and phase transformation of hydrothermal derived sodium titanate. J Am Ceram Soc 95(10):3297-3304

22. Saponjic ZV, Dimitrijevic NM, Tiede DM, Goshe AJ, Zuo X, Chen LX, Barnard AS, Zapol P, Curtiss L, Rajh T (2005) Shaping nanometer-scale architecture through surface chemistry. Adv Mater 17(8):965-971 
23. Morgan DL, Zhu HY, Frost R, Waclawik ER (2008) Determination of morphological phase diagram of titania/titanate nanostructures from alkaline hydrothermal treatment of Degussa P25. Chem Mater 20(12):3800-3802

24. Kurra S, Venkataswamy P, Ravi G, Reddy ChS, Reddy BJ, Vithal M (2019) Enhancement of photocatalytic activity of sodium bismuth titanate by doping with copper, silver, and tin ions. J Inorg Gen Chem 645:1-9

25. Hernández-Hipólito P, García-Castillejos M, Martínez-Klimova E, Juárez-Flores N, Gómez-Cortés A, Klimova TE (2014) Biodiesel production with nanotubular sodium titanate as a catalyst. Catal Today 4(11):220-222

26. Marciniuk LL, Hammer P, Pastore HO, Schuchardt U, Cardoso D (2014) Sodium titanate as basic catalyst in transesterification reactions. Fuel 118:48-54

27. Duan Y, Zhang M, Wang L, Wang F, Yang L, Li X, Wang Ch (2017) Plasmonic Ag-TiO $2-x$ nanocoposites for the photocatalitic removal of NO under visible light with high selectivity: the role of the oxygen vacancies. Appl Catal B: Environ 204(5):67-77

28. Wang LS, Xiao MW, Huang XJ, Wu YD (2009) Synthesis, characterization, and photocatalytic activities of titanate nanotubes surface-decorated by zinc oxide nanoparticles. J Hazard Mater 161(1):49-54

29. Cho SCh, Gyawali G, Adhikari R, Kim TH, Lee SW (2014) Microwave assisted hydrothermal synthesis and characterization of ZnO-TNT composites. Mater Chem Phys 145(3):297-303

30. Benzarouk H, Drici A, Mekhnache M, Amara A, Guerioune M, Bernede JCh, Bendjffal H (2012) Effect of different dopant elements ( $\mathrm{Al}, \mathrm{Mg}$ and $\mathrm{Ni}$ ) on microstructural, optical and electrochemical propertiesof $\mathrm{ZnO}$ thin films deposited by spray pyrolysis (SP). Superlattices Microstruct 52(3):594604

31. Jayaraj MK, Antony A, Ramachandra M (2002) Transparent conducting zinc oxide thin film prepared by off-axis if magnetron sputtering. Bull Materi Sci 25(3):227-230

32. Achour ZB, Ktari T, Ouertan B, Touayar O, Bessais B, Brahim JB (2007) Effect of doping level and spray time on zinc oxide thin films produced by spray pyrolysis for transparent electrodes applications. Sens Actuators A: Phys 134(2):447-451

33. Ma J, He H, Liu F (2015) Effect of Fe on the phtocatalytic removal of NOx over visible light responsive $\mathrm{Fe} / \mathrm{TiO}_{2}$ catalysts. Appl Catal B 179:21-28

34. Dey S, Mehta NS 2020 Automobile pollution control using catalysis. Resour Environ Sustain, 2: 100006

35. Carrera R, Vázquez AL, Arce E, Moran-Pineda M, Castillo S (2007) Photo decomposition of NO by solgel $\mathrm{TiO}_{2}$ catalysts under atmospheric conditions: effect of the method on the textural and morphological properties. J Alloys Compd 434-435:788-791

36. Anpo A, Matsuoka M, Yamashita H (1997) In situ investigations of the photocatalytic decomposition of $\mathrm{NO}_{\mathrm{x}}$ on ion-exhanged silver(I) ZSM-5 catalyts. Catal Today 35(1-2):177-181 
Figures

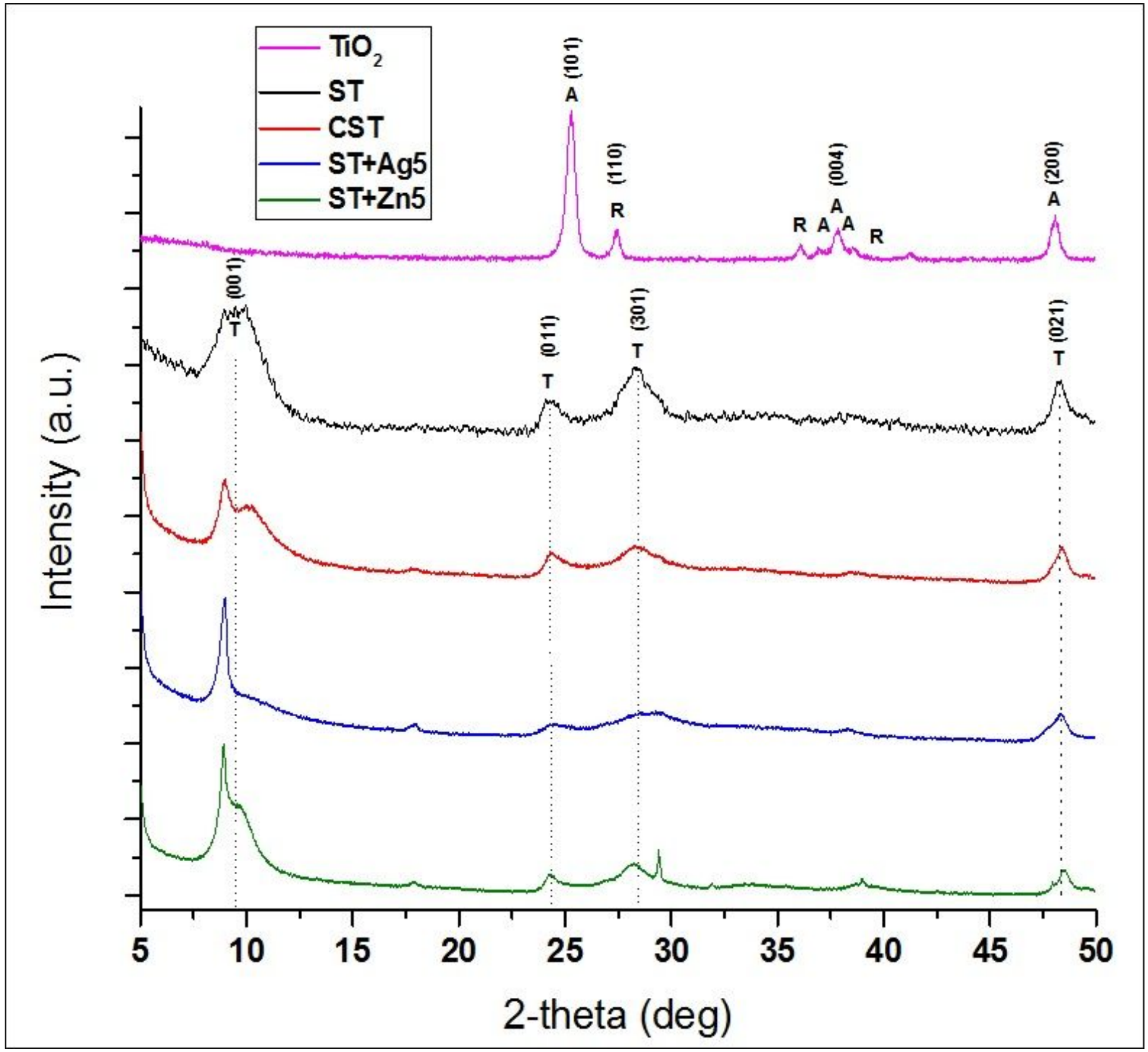

Figure 1

Schematic representation of the experimental arrangement of the continuous flow system for the photocatalytic degradation of NO. 

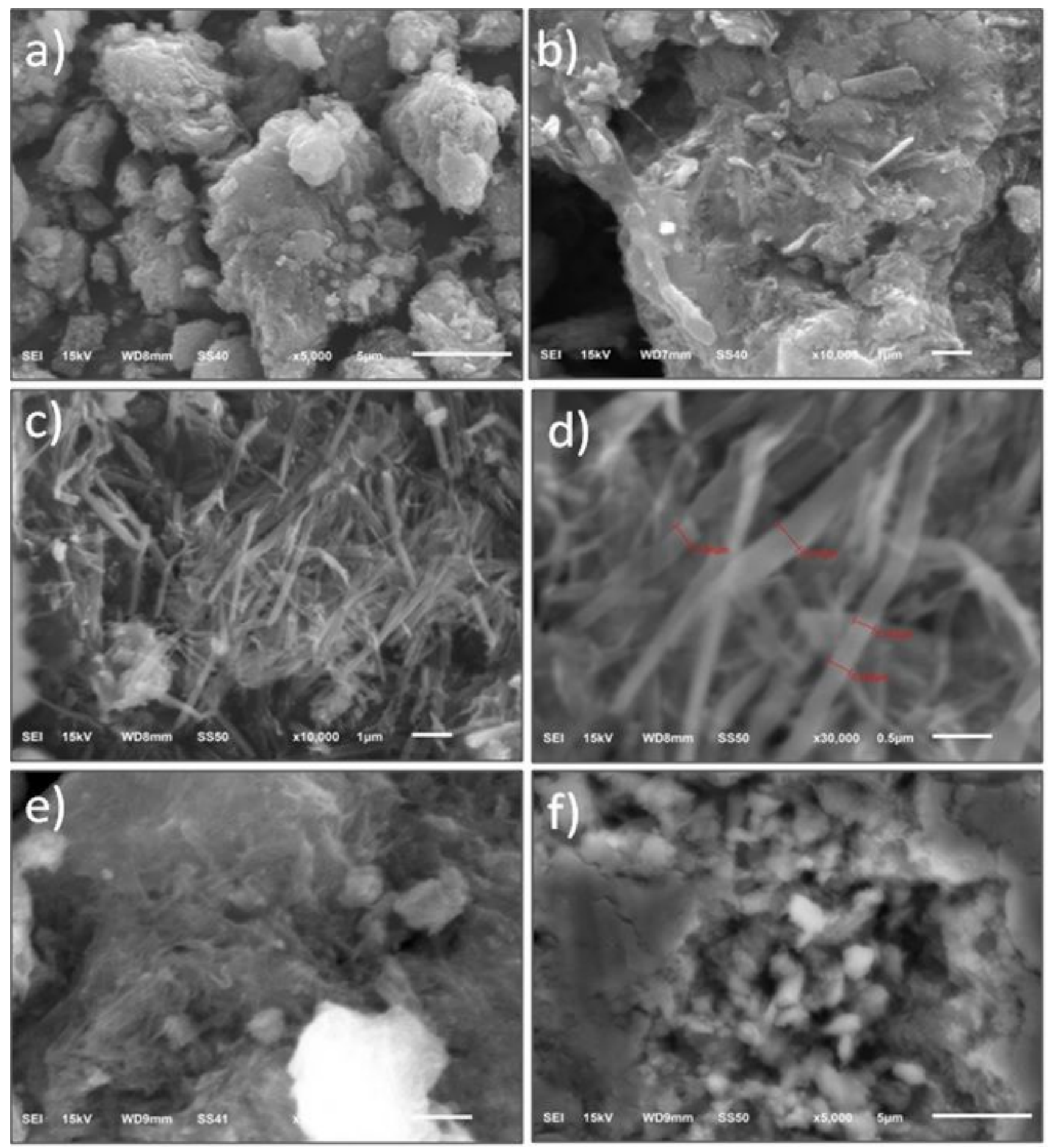

Figure 2

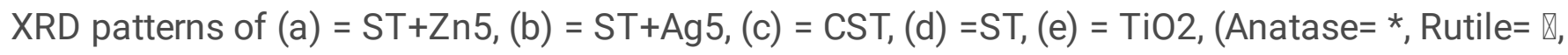
Titanate $=\downarrow$ ). 


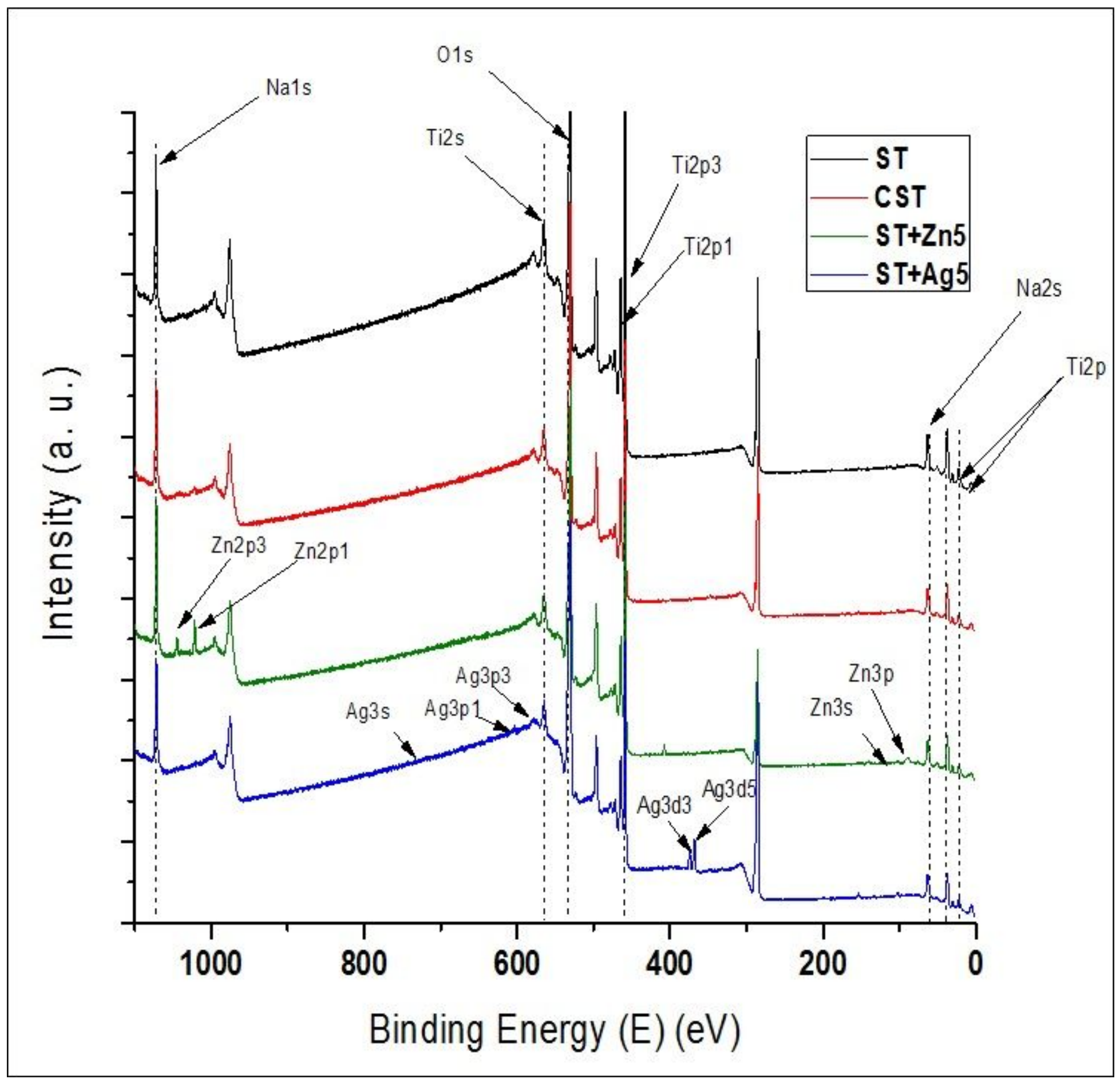

Figure 3

SEM images for the materials prepared in this work. a) and b) ST synthesized from $2.5 \mathrm{M} \mathrm{NaOH}$ solution and 24 hours at $170{ }^{\circ} \mathrm{C} ; \mathrm{c}$ ) and d) ST obtained from $5 \mathrm{M} \mathrm{NaOH}$ solution during 48 hours at $170{ }^{\circ} \mathrm{C} ; \mathrm{e}$ ) ST+Zn5 synthesized from $2.5 \mathrm{M} \mathrm{NaOH}$ solution and 24 hours at $170^{\circ} \mathrm{C}$; f) ST+Zn5 synthesized from 2.5 $\mathrm{M} \mathrm{NaOH}$ solution and 24 hours at $170{ }^{\circ} \mathrm{C}$. 

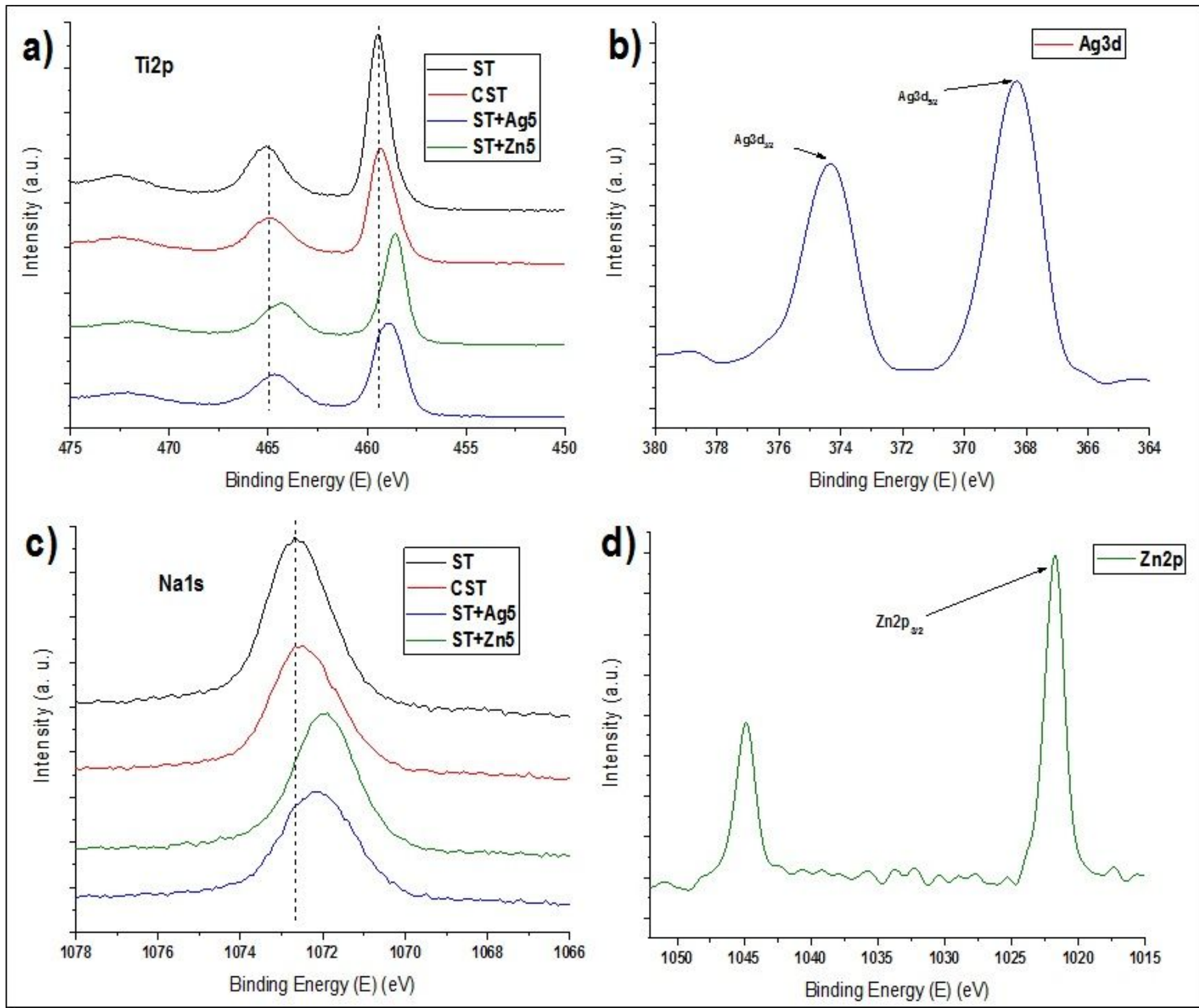

Figure 4

Survey spectra of the prepared ST. a) and b) ST synthesized from $2.5 \mathrm{M} \mathrm{NaOH}$ solution and 24 hours at $170{ }^{\circ} \mathrm{C}$; c) and d) ST obtained from $5 \mathrm{M} \mathrm{NaOH}$ solution during 48 hours at $170{ }^{\circ} \mathrm{C}$; e) ST+Zn5; f) ST+Zn5. 


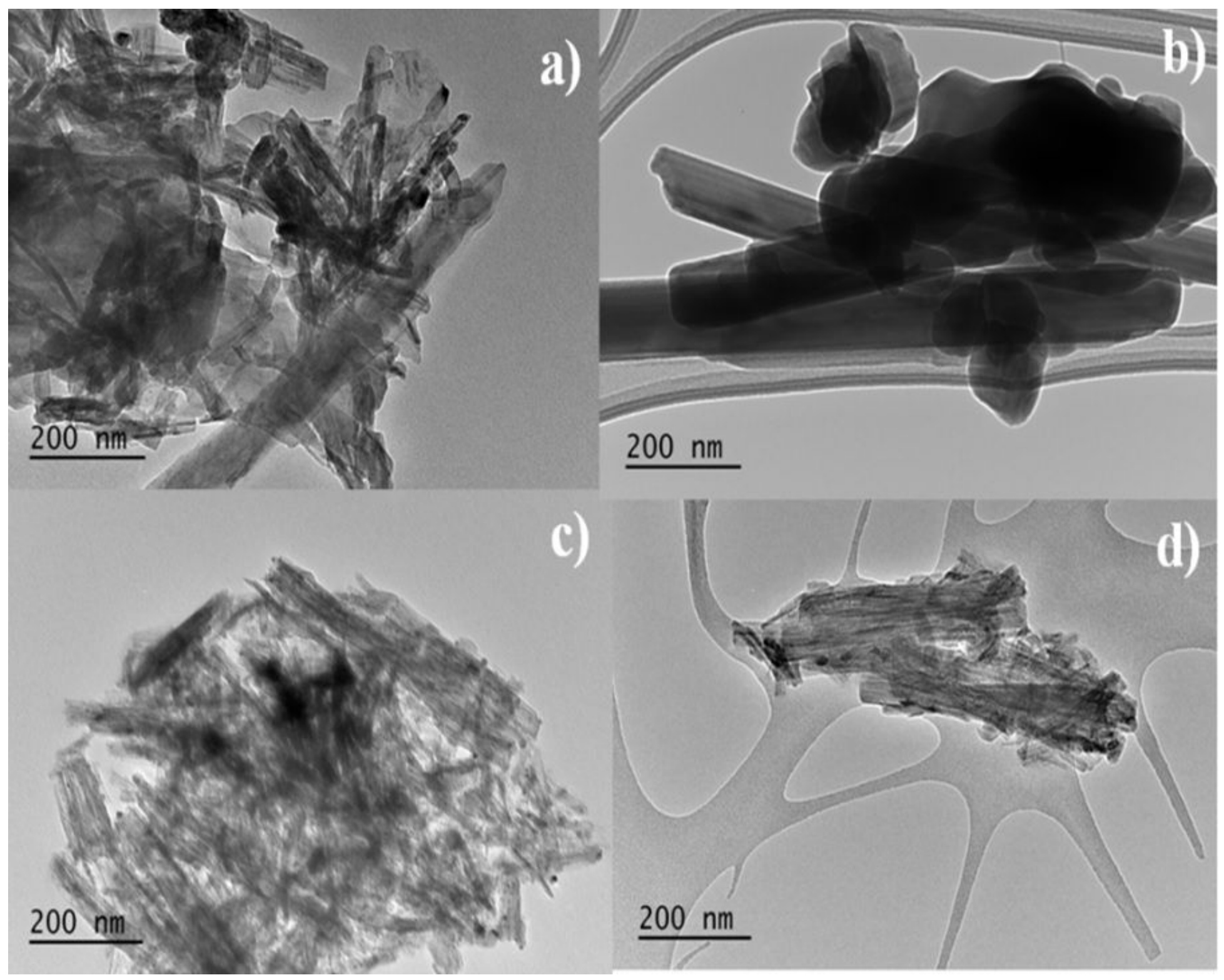

Figure 5

High resolution XPS spectra for a) Ti, b) Ag, c) Na, and d) Zn in ST samples. 


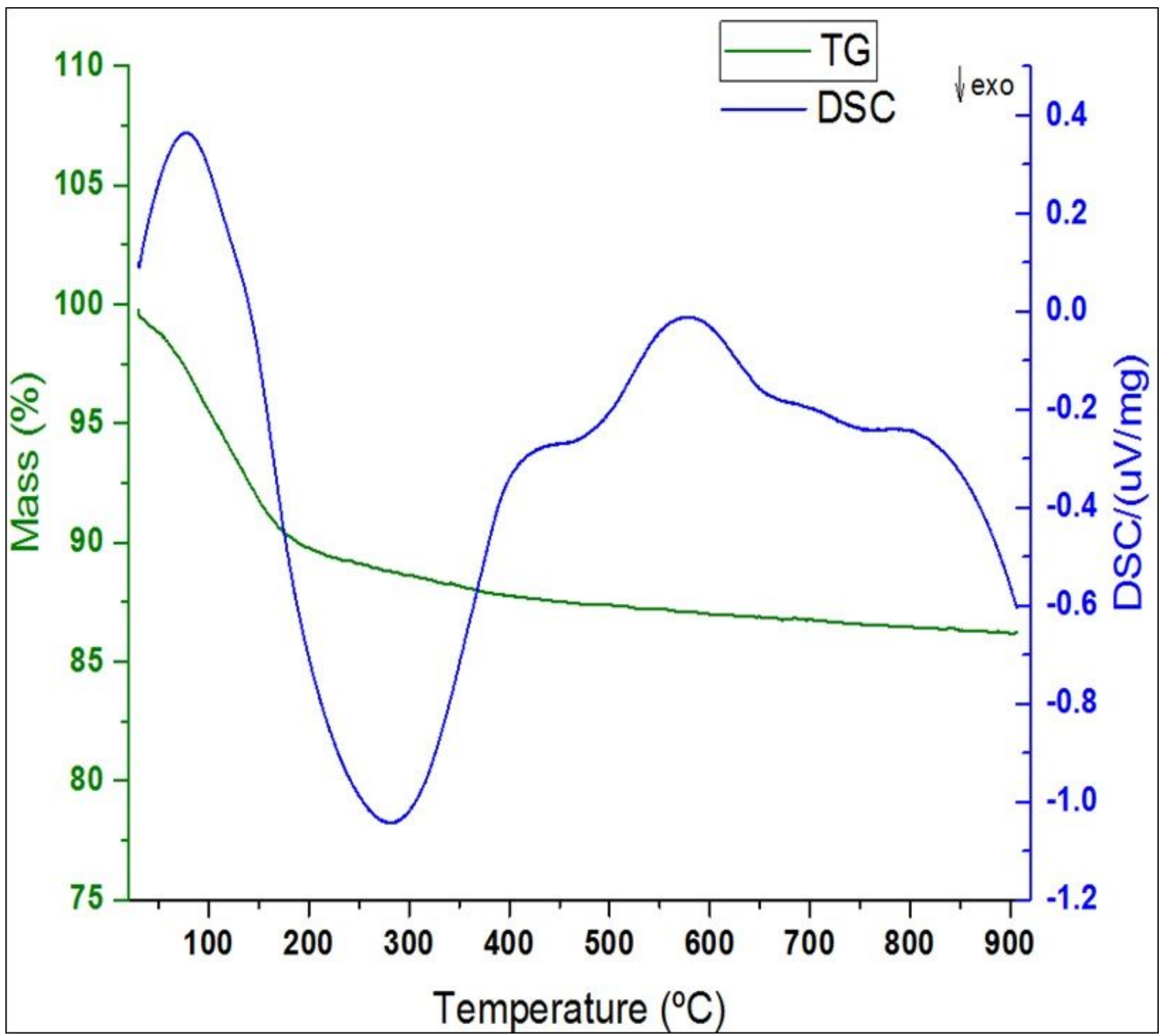

Figure 6

TEM images of a) ST, b) CST, d) ST+5Ag, and d) $S T+5 Z n$. 


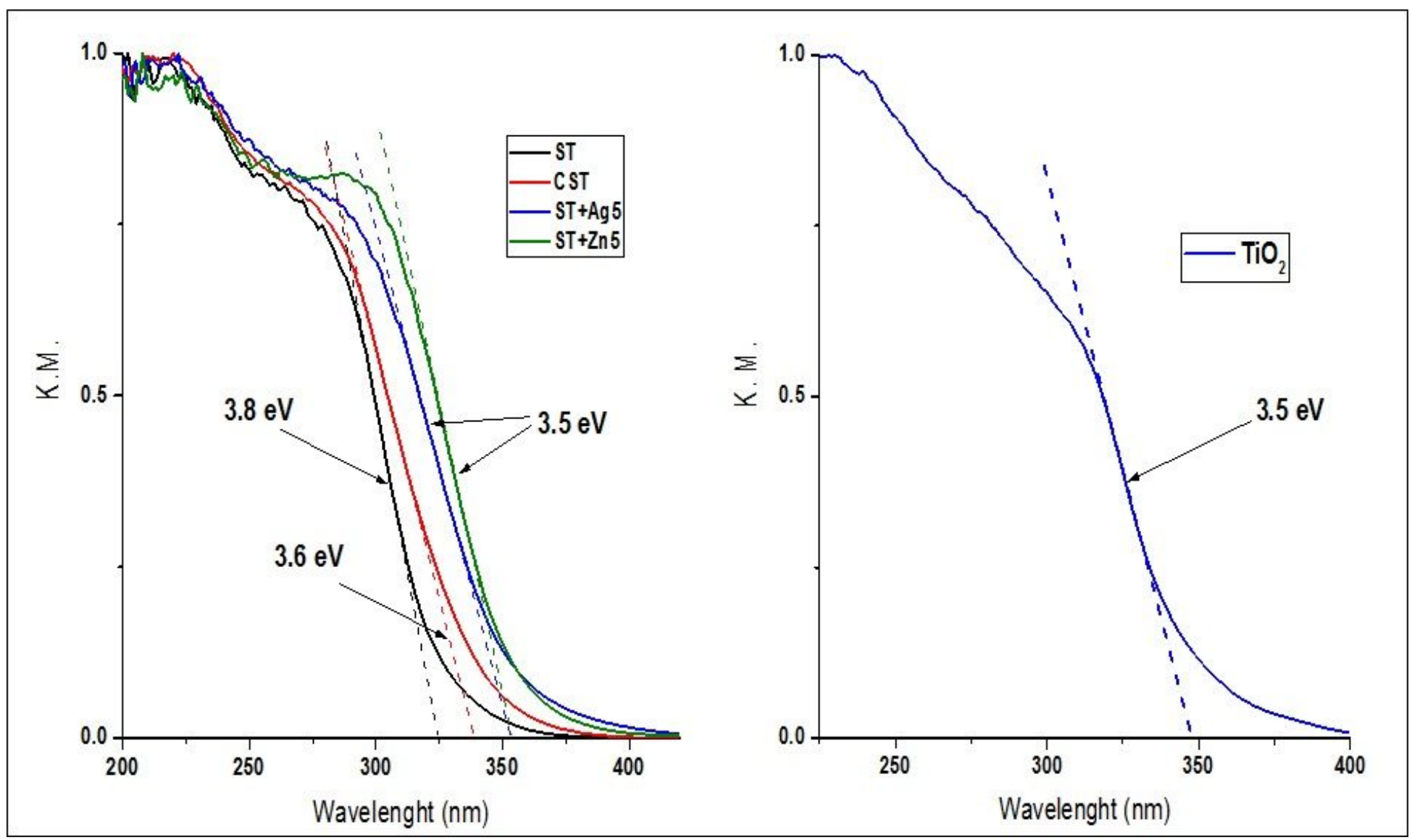

Figure 7

TGA/DSC of ST prepared with $2.4 \mathrm{M} \mathrm{NaOH}, 24 \mathrm{~h}$ and $170{ }^{\circ} \mathrm{C}$.

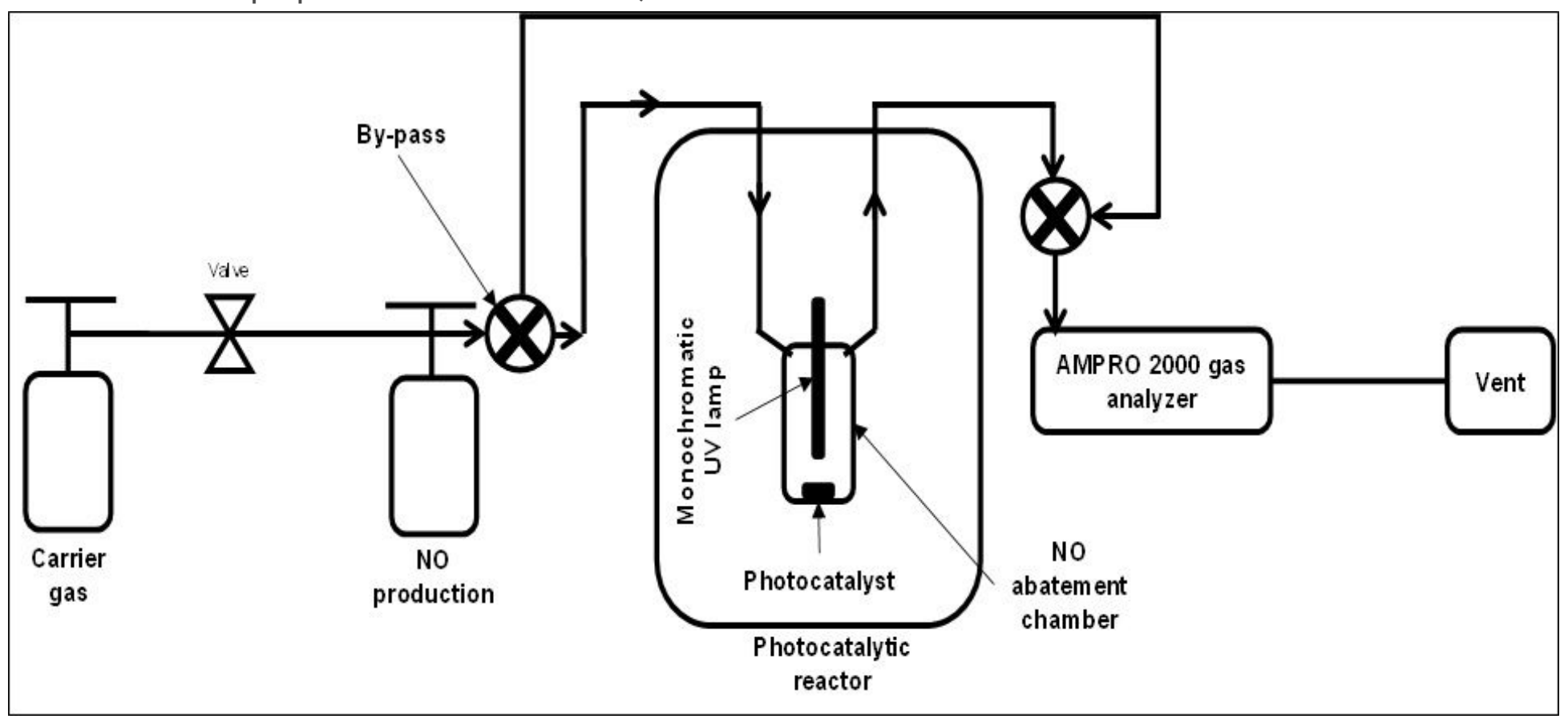

Figure 8

Normalized UV-vis reflectance diffuse spectra (DRS) of ST prepared and TiO2. 


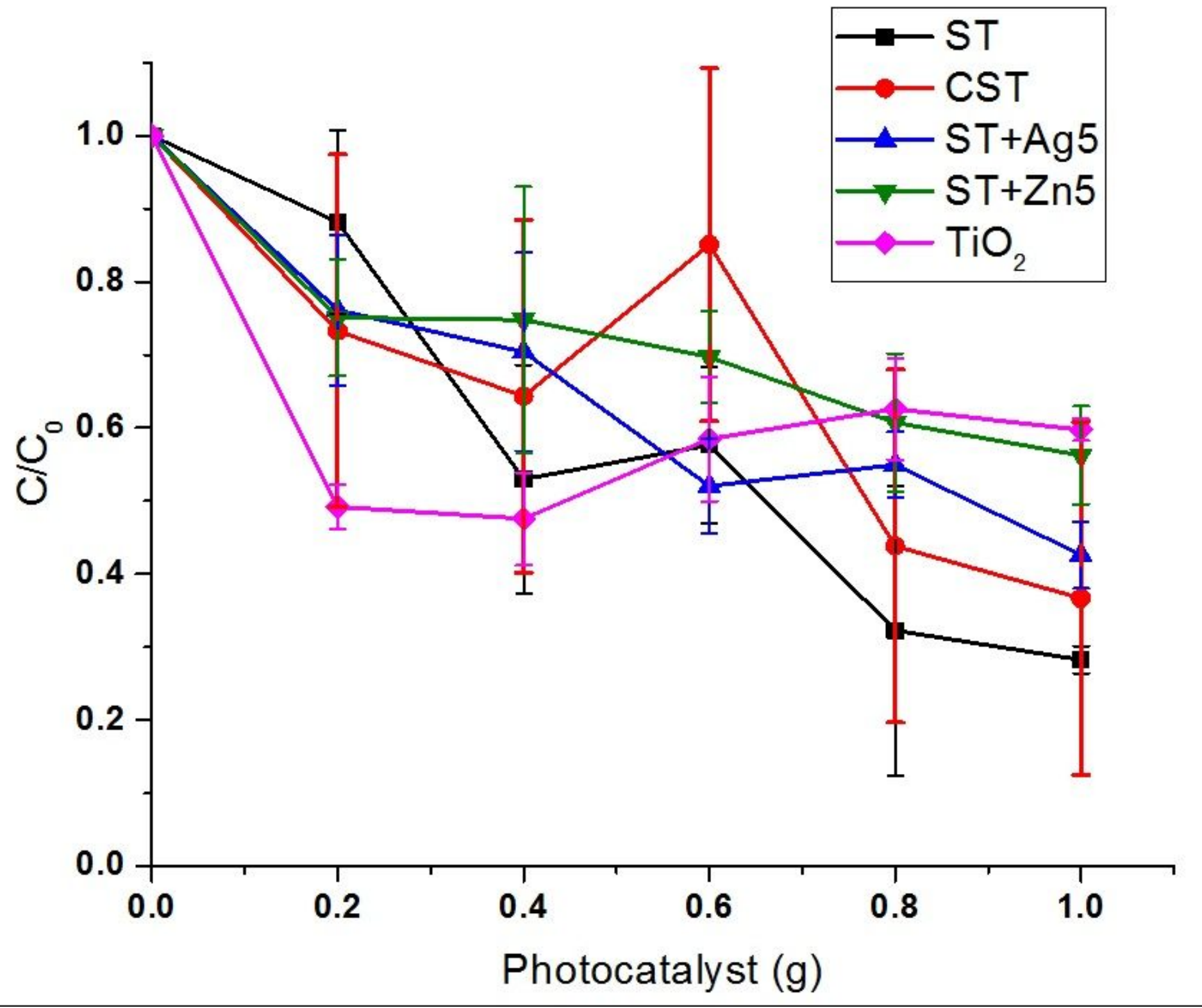

Figure 9

a) NO concentration as a function of the amount of $\mathrm{Cu}$ with and without UV light. a) photocatalytic degradation of $\mathrm{NO}$ from $0.2 \mathrm{~g}$ to $1.0 \mathrm{~g}$ with $0.2 \mathrm{~g}$ increase on average using the different photocatalysts prepared herein. 